\title{
BEHAVIOR OF R.C.C. BEAM WITH CIRCULAR OPENING STRENGTHENED BY CFRP AND GFRP SHEETS
}

\author{
Mithun Kuma $^{1}$, Shivaraj Mangalagi ${ }^{2}$, Rajendrakumar Harsoor $^{3}$ \\ ${ }^{1}$ M-tech Student, ${ }^{2}$ Associate Professor, ${ }^{3}$ Professor, Department of Civil Engineering, P.D.A. College of Engineering, Gulbarga, \\ Karnataka-State, India \\ mithunkumar034@gmail.com,mangalgishivraj@yahoo.com,rsharsoor@rediffmail.com
}

\begin{abstract}
This paper explores the behavior of R.C.C. beam with circular opening strengthened by GFRP and CFRP sheets. In this experimental work ten beams were casted, one beam without opening (i.e. solid beam) and one with circular post opening and considered as control beams. The remaining eight beams were externally strengthened by Carbon fiber reinforced polymer (CFRP) and Glass fiber reinforced polymer (GFRP) sheets with different strengthening schemes i.e. around the opening, inside the opening, inside and around the opening and double layer around the opening. These beams were simply supported and tested less than two points loading in the loading frame. The behaviors of such beams were studied in terms of load carrying capacity, load-deflection behavior and cracking patterns. From the test results it is concluded that the ultimate load carrying capacity of the R.C.C. beam strengthened with GFRP sheets of different schemes were increased in the range of $8.13 \%$ to $45.56 \%$ and beams strengthened with CFRP sheets increased in the range of $13.01 \%$ to $55.32 \%$. Among all the strengthening schemes, the strengthening with CFRP around and inside the opening was found very effective in improving the ultimate load carrying capacity of beam.
\end{abstract}

Keywords: Reinforced concrete beams, Beams with circular opening, CFRP, GFRP, Strengthening schemes, Ultimate load carrying capacity.

\section{INTRODUCTION}

In the construction of multi-storey buildings, many pipes and ducts are necessary to provided for services like water supply, sewage, air-conditioning, electricity, telephone, and computer network. Normally, these pipes and ducts are placed underneath the beam soffit and for aesthetic reasons, are covered by a suspended ceiling, thus creating a dead space. Passing these ducts through transverse openings in the floor beams leads to a reduction in the dead space and results in a more compact design and thus inclusion of openings in beams alters the simple beam behavior to a more complex one. [ 1 and 5].

Strengthening of beams provided with openings depends mainly on whether those openings are pre-planned or postplanned. In the case of pre-planned openings, both the upper and lower chords are designed and reinforced to resist the internal forces that they are subjected to two point loads. The design of such chords depends on the position of opening and the type of loading [1]. A steel reinforcement is provided around the opening edges and extended with enough length beyond the opening corners to resist the stress concentration. Both the reinforcement provided for the upper and lower chords and the steel reinforcement provided around the opening are considered as internal strengthening. Mansur and Hasnat (1979) have defined openings circular, square, or nearly square in shape as small openings, whereas, according to Somes and Corley (1974), a circular opening may be considered as large when its diameter exceeds 0.25 times the depth of the beam web [1].

Quite few methods of strengthening the beams with openings, more common ones are strengthening by Carbon Fiber Reinforced Polymer Sheets (CERP Sheets), Glass Fiber Reinforced Polymer Sheets (GFRP Sheets), Aramid Fiber Reinforced Polymer Sheets (AFRP), Steel Plates and Strengthening by steel reinforcement [3, 4, 5 and 2].

In this paper behavior of beams with opening under different types of strengthening process using CFRP and GFRP Sheets is carried out. Ten beams were casted; nine beams were with circular post opening provided by using drilling machine. Three beams are strengthened with CFRP sheets and three are strengthened with GFRP sheets, two beams are strengthened with CFRP and GFRP sheets respectively by double layer process and remaining one beam with circular post opening (non-strengthened) for comparison. These beams are tested under two point loading in the loading frame, the ultimate failure load of the beam and deflection have been recorded and results were compared with the control beam without opening and control beam with circular post opening. 


\section{EXPERIMENTAL STUDY}

\subsection{Materials}

The mix design for the concrete is carried for M20 grade using OPC 53 grade, local sand and coarse aggregate. The reinforcement in beam consists of 2-12 $\mathrm{mm}$ at bottom, 2-10 $\mathrm{mm}$ at top and $8 \mathrm{~mm}$ stirrups at $150 \mathrm{~mm} \mathrm{c} / \mathrm{c}$. Ten beams were casted and cured for 28 days. The post openings of size 100 $\mathrm{mm}$ diameter were provided by using drilling machine and one solid beam (i.e. control beam). The CFRP and GFRP sheets were used for the external strengthening of the beam with circular opening and these sheets were bonded to the specimen by using epoxy resin.

\subsection{Test Specimen}

The experimental program includes testing of beams with circular opening having different strengthening techniques. All tested beams had a rectangular cross section of $150 \mathrm{~mm}$ width and $250 \mathrm{~mm}$ depth and a effective length of $1800 \mathrm{~mm}$. The dimension and location of the opening as shown in figure 1.

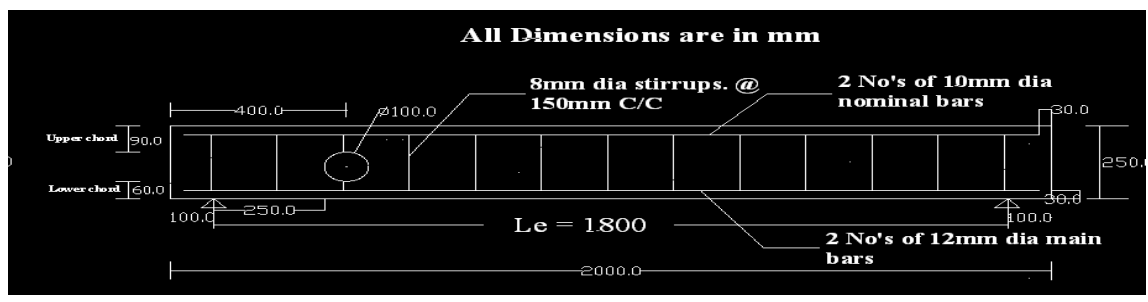

Fig. 1: Dimension of beam with circular opening in shear zone

\subsection{Strengthening schemes with CFRP and GFRP}

\section{Sheets}

- Strengthening around the opening (wrapping of CFRP and GFRP sheets around the opening): The CFRP sheet is bonded only around the opening for B3 beam and GFRP sheet for B4 beam and has been extended $200 \mathrm{~mm}$ beyond the opening.

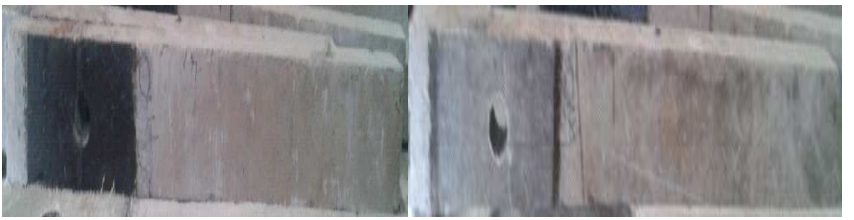

\section{CFRP wrapping around GFRP wrapping around the opening the opening}

- $\quad$ Strengthening inside the opening (wrapping of CFRP and GFRP sheets inside the opening): The CFRP sheet is bonded only inside the opening for B5 beam and GFRP sheet for B6 beam.

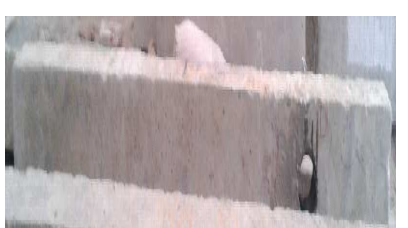

CFRP wrapping inside the opening

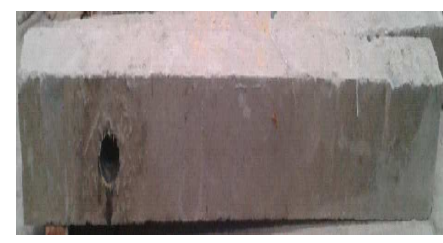

GFRP wrapping inside the opening
- Strengthening around and inside the opening (wrapping of CFRP and GFRP sheets around and inside the opening): The CFRP sheet is bonded both around and inside the opening for B7 beam and GFRP sheet for B8 beam and extended 200mm beyond the opening.

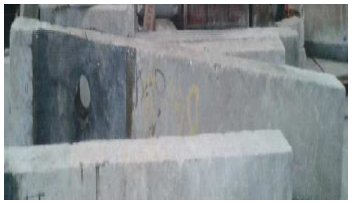

CFRP wrapping around and inside the opening

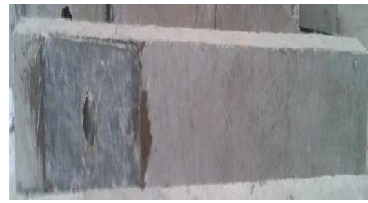

GFRP wrapping around and inside the opening
- Strengthening around the opening by double layer (wrapping of CFRP sheet and GFRP sheets around the opening by double layer process): In this technique CFRP sheet is bonded only around the opening by double layer process for B9 beam and GFRP for B10 beam and extended $200 \mathrm{~mm}$ beyond the opening.

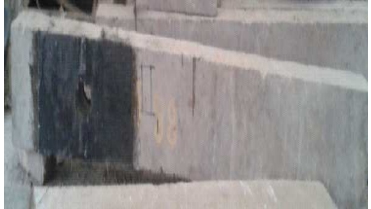

CFRP wrapping around

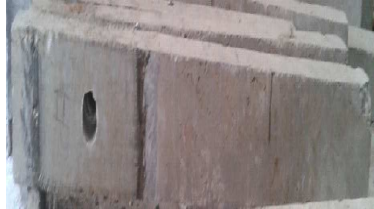

GFRP wrapping around the opening by double layer the opening by double layer 


\subsection{Loading Set Up and Instrumentations}

The schematic of the test set up as shown in figure 2. The beams were tested in loading frame (1000 kN capacity) under two point loading. The load was applied incrementally by means of hydraulic jack until beam fails. The deflection at mid span, opening centre and other end without opening were recorded.

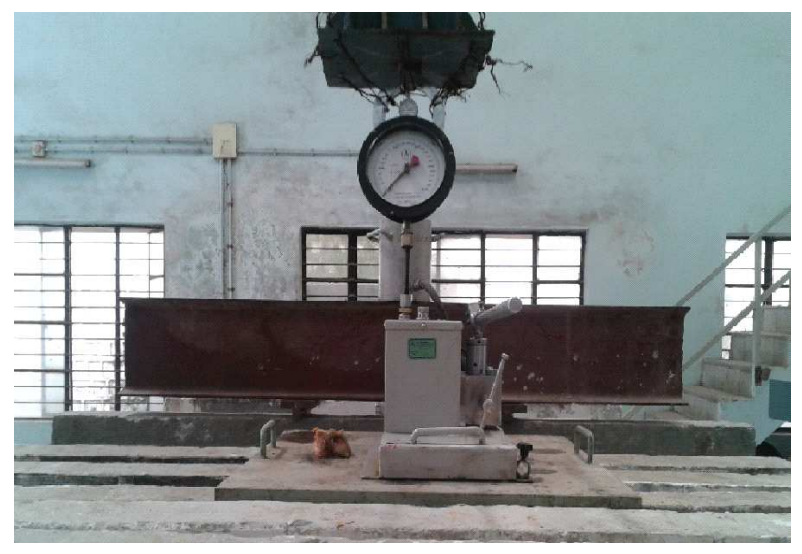

\section{TEST RESULTS AND DISCUSSIONS}

\subsection{Test Results}

The test results are summarized in Table 2. The table shows initial crack load, ultimate failure load, maximum deflection and modes of failure for all the beams.

Fig. 2: Test set up in loading frame

Table 2: Test results

\begin{tabular}{|c|l|c|c|c|c|c|}
\hline $\begin{array}{c}\text { Designation } \\
\text { on Beam }\end{array}$ & \multicolumn{1}{|c|}{ Type of Strengthened } & $\begin{array}{c}\text { Initial } \\
\text { Crack } \\
\text { Load in } \\
\text { KN }\end{array}$ & $\begin{array}{c}\text { Ultimate } \\
\text { Failure } \\
\text { Load in } \\
\text { KN }\end{array}$ & $\begin{array}{c}\text { Increase in } \\
\text { load } \\
\text { carrying } \\
\text { capacity in } \\
\text { \% }\end{array}$ & $\begin{array}{c}\text { Maximum } \\
\text { Deflection }\end{array}$ & $\begin{array}{c}\text { Mode of } \\
\text { Failure }\end{array}$ \\
\hline B1 & Control beam & 27.10 & 79.75 & - & 10.895 & Flexure \\
\hline B2 & $\begin{array}{l}\text { Non Strengthened Control } \\
\text { beam(post opening) }\end{array}$ & 19.00 & $* 49.78$ & - & 5.550 & Shear \\
\hline B3 & $\begin{array}{l}\text { Strengthened around by } \\
\text { CFRP }\end{array}$ & 22.24 & 67.60 & 35.79 & 7.025 & Shear \\
\hline B4 & $\begin{array}{l}\text { Strengthened around by } \\
\text { GFRP }\end{array}$ & 20.62 & 61.12 & 22.78 & 9.230 & Shear \\
\hline B5 & $\begin{array}{l}\text { Strengthened inside by } \\
\text { CFRP }\end{array}$ & 19.81 & 56.26 & 13.01 & 6.825 & Shear \\
\hline B6 & $\begin{array}{l}\text { Strengthened inside by } \\
\text { GFRP }\end{array}$ & 19.81 & 53.83 & 8.13 & 6.850 & Shear \\
\hline B7 & $\begin{array}{l}\text { Strengthened around and } \\
\text { inside by CFRP }\end{array}$ & 23.86 & 77.32 & 55.32 & 9.925 & Flexure \\
\hline B8 & $\begin{array}{l}\text { Strengthened around and } \\
\text { inside by GFRP }\end{array}$ & 22.24 & 72.46 & 45.56 & 7.850 & Flexure \\
\hline B9 & $\begin{array}{l}\text { Strengthened around with } \\
\text { double layer by CFRP }\end{array}$ & 23.86 & 74.89 & 50.44 & 8.210 & Flexure \\
\hline B10 & $\begin{array}{l}\text { Strengthened around with } \\
\text { double layer by GFRP }\end{array}$ & 23.86 & 70.03 & 40.67 & 7.495 & Flexure \\
\hline
\end{tabular}

\subsection{Discussion}

Examining the results presented in the table 2, it is clear that the presence of an opening not only reduced the load carrying capacity of the beam but also reduce the stiffness of the beam. The reduction in the load carrying capacity of the beam was about $37.58 \%$ due to presence of a $100 \mathrm{~mm}$ diameter circular 
opening within the shear zone. The percentage of increase in load carrying capacity for the beams strengthened with CFRP(B7) and GFRP(B8) sheets around and inside the opening was $55.32 \%$ and $45.56 \%$ respectively as compared to non-strengthened beam B2 (control beam with circular post opening) and in case of beams strengthened with CFRP(B9) and GFRP(B10) sheets around the opening by double layer, the percentage of increase in load carrying capacity was $50.44 \%$ and $40.88 \%$ respectively as compared to nonstrengthened beam B2 (control beam with circular post opening).

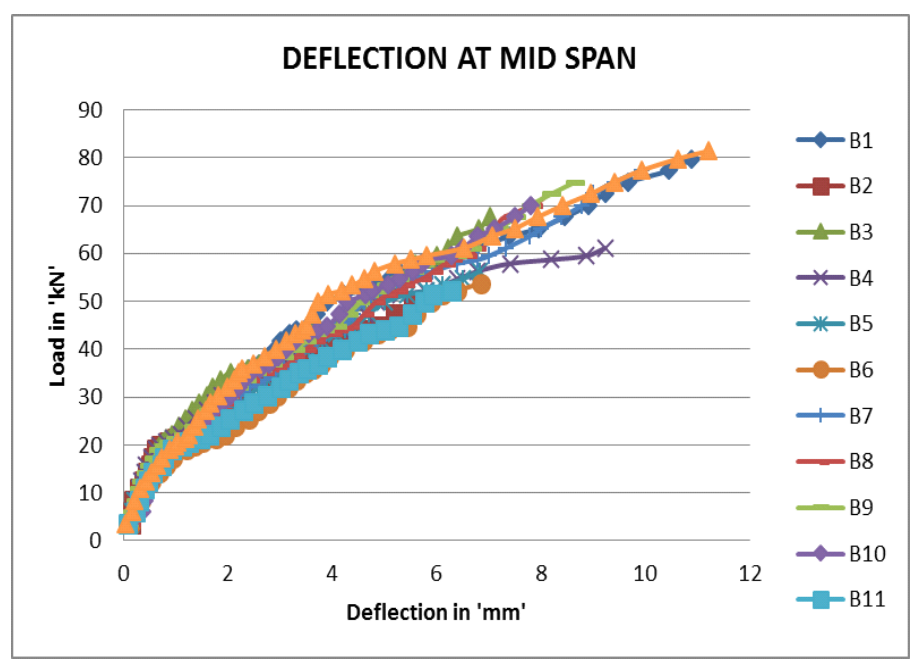

Fig. 3: Load-deflection relationship for all beams at mid span

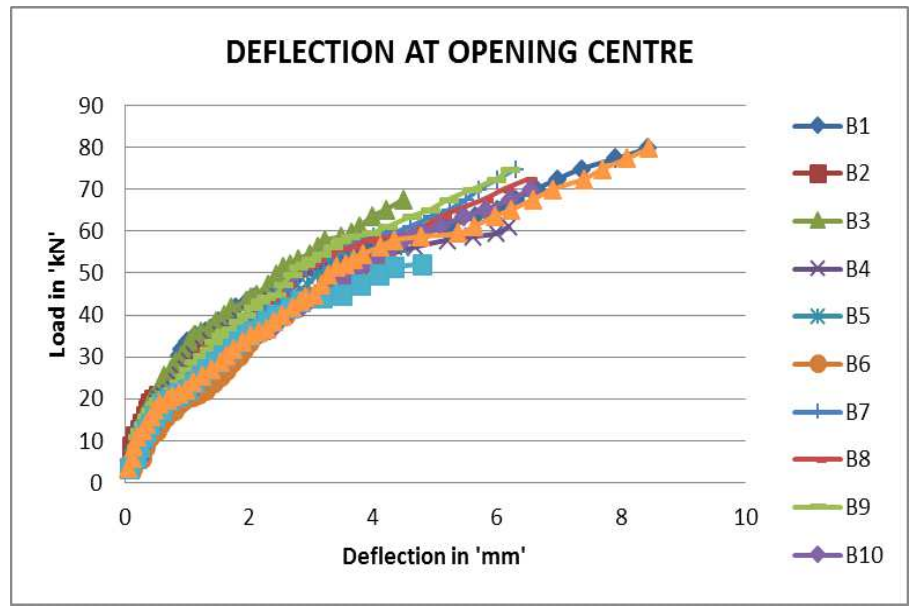

Fig. 4: Load-deflection relationship for all beams at the opening centre

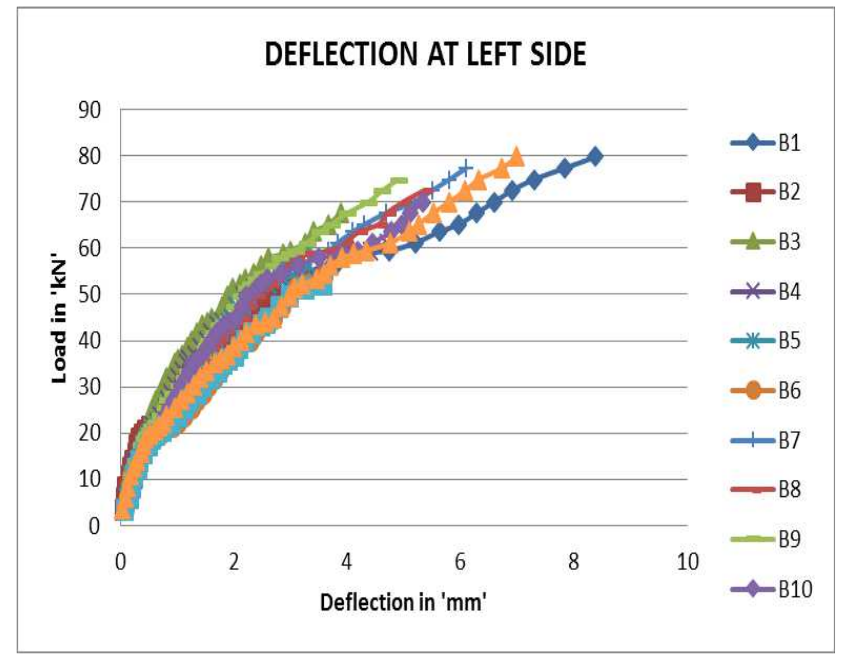

Fig. 5: Load-deflection relationship for all beams at left side

The figure 3 shows load-mid-span deflection relationship for all tested beams. Comparing the deflection for beams B1 and B2 it can be seen that a significance increase in the mid-span deflection for beams B2 than that for beam B1. This is due to the reduction in the stiffness of beam $\mathrm{B} 2$ as result of the inclusion of opening. The figure 4 shows load deflection relationship for all tested beams with openings at centre of the opening. It can be seen that external strengthening around and inside the opening significantly increases the beam stiffness at the opening, increase in the load carrying capacity and decrease in deflection as compared to non strengthened beam B2. It can be also observed from the figure 3, 4 and 5 that within the elastic range of loading, the behavior of all strengthened beams with opening were similar to that of the solid beam B1.

\section{CONCLUSIONS}

- By an inclusion of circular post opening in the beam the load carrying capacity of the beam decreases by $37.57 \%$ as compared to solid beam i.e. control beam due to decrease its stiffness and diagonal cracks were developed due to stress concentration around the opening edges.

- $\quad$ Strengthening of the beam opening with CFRP and GFRP sheets around the opening is more efficient than strengthening of the beam opening with CFRP and GFRP sheets inside the opening.

- $\quad$ Strengthening of the beam opening by using CFRP and GFRP sheets both around and inside the opening increases the load carrying capacity significantly and in case of CFRP sheets percentage of increase in load carrying capacity is $55.32 \%$, where as in case of GFRP sheets percentage of increase in load carrying capacity is $45.56 \%$.

- From the overall study, it can be concluded that the strengthening with CFRP around and inside the 
opening increases ultimate load carrying capacity and this was best strengthening scheme among all the strengthening process.

\section{REFERENCES}

[1] M.A.Mansur, "Design of Reinforced Concrete Beams with Web Openings", Proceedings of the $6^{\text {th }}$ Asia Pacific Structual Engineering and Construction Conference (APSEC 2006), 5-6 September 2006, Kuala Lumpur, Malaysia.

[2] G. Niea, C.S. Caib, H. Wua, J.S. Fana, "Experimental and Theoretical Study of Steel-Concrete Composite Beams With Openings in Concrete Flange", J. Engineering Structures 28 (2006) 992-1000.

[3] R.Balamuralikrishna and C.Anthony Jeyasehar.Senior, "Flexural Behaviour Of RC Beams Strengthened With Carbon Fibre Reinforced Polymer (CFRP) Fabrics", the open civil engineering Journal, 2009, 3,102-109.

[4] Subhajit Mondal, J.N.Bandyapadhya and Chandra Pal Gautam, "Strengthening and Rehabilitation of Reinforced Concrete Beams with Opening", India. International Journal of Civil and Structural Engineering, Volume-2, No.1,20011.

[5] Soroush Amiri and Reza Masoudnia, "Investigation of the Opening Effects on the Behaviour of Concrete Beams without Additional Reinforcement in Opening Region Using Fem Method", Australian Journal of Basic and Applied Sciences, 5 (5): 617-627, 2011.

[6] Soroush Amiri, Reza Masoudnia and Ali Akbar Pabarja, "The Study of the Effects of Web Openings on the Concrete Beams", Australian Journal of Basic and Applied Sciences, 5 (7): 547-556, 2011. 